\title{
Ação afirmativa, relações raciais e educação básica*
}

\author{
Ana Lúcia Valente \\ Universidade de Brasília, Faculdade de Agronomia e M edicina Veterinária
}

\section{Introdução}

No Brasil, estudos realizados nas interfaces da educação e das relações interétnicas expuseram as dificuldades enfrentadas pelas crianças negras no siste-

* Este texto recupera parte importante de artigo publicado nos Cadernos de Pesquisa no 93 (maio de 1995, p. 40-50). Em razão do atual movimento para a promoção de ações afirmativas para negros e da dificuldade manifestada por pesquisadores de acesso àquele artigo, publicado há dez anos, resolvi encaminhá-lo em outro formato para publicação. A proposta metodológica ali contida foi fruto de reflexão com o professor Jorge Manhães, da Universidade Federal de Mato Grosso do Sul (UFMS) e militante do grupo Trabalho e Estudos Zumbi (TEZ) organização negra que atua em Mato Grosso do Sul (MS). A dissertação de mestrado de Lucimar Rosa Dias, Diversidade étnico-racial e educação infantil: três escolas, um problema, várias respostas, defendida em 1997 no Programa de Pós-Graduação em Educação da UFMS, e a "cartilha" Sou preto da linda cor, produzida em Belo Horizonte (MG), pela Creche Comunitária Caiçaras (2001), foram elaboradas a partir dessa proposta. ma escolar, indicando a necessidade de serem encontrados mecanismos de combate ao preconceito e discriminação raciais ao nível da socialização primária e secundária, ou seja, na família e na escola. Para a superação do problema, destacam a importância de serem elaboradas novas propostas e materiais didáticos para enfrentar a questão, e a construção de uma identidade negra positiva que se construa na relação com o branco e no reconhecimento da diferença. Grande parte das propostas curriculares para o enfrentamento do preconceito e da discriminação raciais, dirigidas para o ensino fundamental e médio, volta-se para o ensino de História. Outras são desenvolvidas a partir de experiências educacionais de grupos e entidades negras organizadas, em interação com o sistema formal e oficial de ensino. Mesmo que possam ser consideradas insuficientes, o certo é que estas propostas rompem com a imobilidade. Entretanto, tais iniciativas enfrentam dificuldades de incorporação efetiva. Dentre essas dificuldades, pode-se destacar as encontradas nos cursos de formação de professores.

Apesar dos avanços expressivos promovidos na avaliação dos livros didáticos, para evitar preconcei- 
tos e outros equívocos, e nos Parâmetros Curriculares Nacionais, que têm um capítulo dedicado ao pluralismo cultural enfatizando a "necessidade imperiosa da formação dos professores no tema" (Brasil, Ministério da Educação, 1997, p. 4; Valente, 2003a), urge encontrar e definir medidas para os professores intervirem na questão racial. Embora esses parâmetros representem um avanço considerável rumo ao tratamento eficaz da questão, uma vez que os dispositivos legais até então existentes mantêm-se prudentemente no campo das formulações abstratas, seja na Constituição, seja na Lei de Diretrizes e Bases da Educação Nacional (LDB) ${ }^{1}$ (Valente, 1998), ainda são reticentes as propostas de combate ao racismo e pouco delineadas as medidas concretas de abordagem. De nada adianta dispor de livro didático e currículo apropriados se o professor for preconceituoso, racista, e não souber lidar adequadamente com a questão. Uma proposta de formação/capacitação dos professores para trabalhar com a temática é capaz de enfrentar o desafio lançado para a implementação da lei no 10.639 (Brasil, Congresso Nacional, 2003) - a Lei Ben Hur² -, que

${ }^{1}$ Em 2004, a LDB foi alterada nos seus artigos 26 e 79, por força da lei $n^{\circ} 10.639$, que estabelece as Diretrizes Curriculares Nacionais para a Educação das Relações Étnico-Raciais e para o Ensino de História e Cultura Afro-Brasileira e Africana.

${ }^{2}$ Ben Hur é militante negro, vinculado ao grupo TEZ, e exdeputado federal pelo Mato Grosso do Sul. Foi quem propôs o projeto de lei com a também deputada federal Esther Grossi, ambos do Partido dos Trabalhadores (PT). Propor que a lei n ${ }^{\circ} 10.639$ seja assim nomeada significa respeitar as orientações do parecer $n^{\circ}$ CNE/CP 003/2004, cuja relatora foi Petronilha Beatriz Gonçalves e Silva. Nos termos desse parecer que instituiu as Diretrizes Curriculares Nacionais para a Educação das Relações ÉtnicoRaciais e para o Ensino de História e Cultura Afro-Brasileira e Africana, o ensino de História e de Cultura Afro-Brasileira far-seá por diferentes meios, inclusive a realização de projetos de diferentes naturezas, no decorrer do ano letivo, com vistas à divulgação e estudo da participação dos africanos e de seus descendentes em episódios da história do Brasil, na construção econômica, social e cultural da nação, destacando-se a atuação de negros torna obrigatório o ensino da história e da cultura afrobrasileira no currículo oficial das escolas públicas.

Com base em proposta metodológica de combate ao racismo na educação básica, desenvolvida com resultados positivos em escolas de Campo Grande (MS) e Belo Horizonte (MG), pretende-se:

a) indicar que esse nível de escolarização apresenta o quadro educacional mais grave para as crianças negras;

b) refletir sobre as políticas afirmativas de caráter universal e específico, nos diferentes níveis de ensino, defendendo a perspectiva de que contrapô-las, como se excludentes fossem, é uma falsa questão;

c) argumentar que a maior ou menor eficácia de políticas de ação afirmativas para os negros está inversamente relacionada ao nível de ensino, isto é, quanto antes o racismo, a discriminação e o preconceito forem enfrentados, melhores serão os resultados educacionais; e

d) apontar os desafios para a formação de professores nessa perspectiva.

\section{Da teoria à intervenção}

Embora a coibição de manifestações de racismo seja imprescindível no plano legal, conquistas e avanços alcançados nessa direção não bastam para transformar as concepções arraigadas no imaginário da

em diferentes áreas do conhecimento, de atuação profissional, de criação tecnológica e artística de luta social, tais como: Zumbi, Luiza Nahim, Aleijadinho, Padre Maurício, Luiz Gama, Cruz e Souza, João Cândido, André Rebouças, Teodoro Sampaio, José Correia Leite, Solano Trindade, Antonieta de Barros, Edison Carneiro, Lélia Gonzáles, Beatriz Nascimento, Milton Santos, Guerreiro Ramos, Clóvis Moura, Abdias do Nascimento, Henrique Antunes Cunha, Tereza Santos, Emmanuel Araújo, Cuti, Alzira Rufino, Inaicyra Falcão dos Santos, entre outros (Brasil, Conselho Nacional de Educação, 2004, p. 12). Entre esses outros, Ben Hur, na política partidária. 
população brasileira. Em razão disso, muitos estudiosos das relações interétnicas e militantes de grupos negros organizados no país têm apontado para a necessidade de se dar maior atenção ao processo educativo que se desenvolve em várias instâncias da convivência humana. É no transcorrer desse processo que se cristalizam concepções falsas sobre os negros também internalizadas pelo grupo étnico, dificultando a construção de uma identidade positiva, capaz de contrapor-se às concepções negativas, elaboradas historicamente pelos grupos brancos dominantes.

Os estudos que buscaram analisar as interfaces entre educação e relações interétnicas apresentam indicativos bastante preocupantes. Podem ser destacados os seguintes: mantendo-se constante o nível de instrução, maior número de brancos encontra-se empregado, em comparação ao número de negros; os negros possuem um percentual maior de analfabetos, quando comparados aos contingentes de pardos e brancos na mesma situação; os índices e a incidência de exclusão e de repetência são superiores entre os negros; as crianças negras que permanecem na escola têm uma trajetória irregular, marcada por maior número de interrupções em relação à criança branca; o atraso escolar é menor entre os brancos, e essa diferença vai-se tornando mais dramática à medida que aumenta a idade do aluno; o aluno negro ou o aluno pobre é absorvido pela rede escolar de maneira diferente do aluno de classe média ou não-pobre e, uma vez constituída essa clientela, os professores atuam no sentido de reforçar a crença de que os alunos pobres e negros não são educáveis; há um ritual pedagógico que exclui a história de luta dos negros, impõe um ideal de ego branco, folcloriza a cultura negra mas, no discurso, propugna a igualdade entre as crianças, independentemente de cor; os livros didáticos discriminam os negros e falta material de apoio que auxilie aos professores a enfrentar o preconceito e a discriminação intra-escolares; a escola não auxilia a formação da identidade racial e, além disso, reforça de forma negativa alguns estereótipos que prejudicam o processo socializador.

Em que pese a contribuição oferecida por esses estudos, a criança tem sido negligenciada pela refle- xão sobre o grupo negro no Brasil. Entretanto, podese considerar que um contingente expressivo de crianças negras vem substituindo a "casa" pela "rua", porque são pertencentes às camadas mais carentes da população nacional, apresentando dificuldades de acesso à socialização primária, fazem parte de famílias que têm sua organização afetada pela carência econômica, e são constantemente acuadas pelo preconceito e discriminação raciais. Tratadas com suspeição, como se essas crianças tivessem um potencial seguro para a delinquiência, a presença e atitudes delas acabam por reforçar o estigma racial. Considerandose também o baixo índice de escolaridade do negro ante outros segmentos étnicos da população brasileira, as chances de acesso à educação formal e sistemática são menores para a criança negra. Esse quadro é ainda mais grave quando se considera a educação infantil, nível da educação básica, considerada hoje pelos pedagogos como indispensável para o êxito nos estudos posteriores. Esse nível educacional tem sido inacessível ao grupo negro, quer por não ser satisfatoriamente atendido pelo Estado, quer por razões econômicas quando ministrado em escolas particulares. As raras famílias negras que têm condições de arcar com esses custos enfrentam a discriminação velada de escolas que impedem o ingresso de suas crianças. Nesse sentido, a educação infantil seria duplamente seletiva: social e racialmente (Pereira, 1987).

Corroborando a afirmação de que é nesse nível da educação básica que se apresenta o quadro educacional mais grave para as crianças negras, as propostas curriculares para o enfrentamento do preconceito e discriminação raciais são dirigidas para o ensino fundamental e médio, e são especialmente voltadas para o ensino de História. Também as experiências educacionais de grupos e entidades negras organizadas, mesmo quando desenvolvidas em interação com o sistema de ensino regular, enfrentam dificuldades de incorporação efetiva e acabam por atender, basicamente, a uma clientela cuja faixa etária tem mais de 7 anos.

Com base nas dificuldades apontadas por esses estudos e no conhecimento sobre a conformação das relações entre brancos e negros no Brasil, tenho refletido sobre a importância de serem desencadeadas 
ações mais pragmáticas, no sentido de "equipar" a sociedade e, em especial, a escola, para progressivamente enfrentar a questão racial.

\section{U ma proposta metodológica}

Construir uma proposta com a expectativa de interferir no processo de desenvolvimento de crianças brancas e negras, em um momento decisivo, coloca-se como um grande desafio, envolvendo necessariamente não apenas as crianças, mas sobretudo os educadores na escola e na família.

Deve-se salientar que a presença da professora é marcante para as crianças que estão na faixa etária correspondente à educação infantil. Investir em um trabalho de orientação de educadores que atendem esse nível de escolarização, sobretudo daqueles mais sensíveis e interessados em desmistificar idéias falsas sobre os negros, cristalizadas no imaginário da população, pode ser fundamental para enfrentar a questão racial. $\mathrm{O}$ investimento maior em professores sensíveis ao problema é uma opção tática, na medida que a sua "instrumentalização" é mais rápida e, a partir disso, a tarefa de envolver os professores mais renitentes é facilitada.

Considerando-se a possibilidade de veiculação dessas falsas idéias no âmbito familiar, o processo educacional escolar, balizado na compreensão correta das relações interétnicas no país, pode provocar um impasse pedagógico. Tal impasse, estabelecido entre a concepção aprendida na escola e o preconceito entranhado nas práticas e noções familiares, pode ser enfrentado, num segundo momento, também com a interferência da escola. O círculo vicioso instaurado por uma educação preconceituosa recorrente pode vir a ser quebrado, já que o educador pode e deve ser reeducado. Por sua vez, mediante palestras para o esclarecimento dos pais sobre o trabalho pedagógico desenvolvido pela escola, no tocante à questão racial, é possível construir-se "solidariedades" que tornem o combate às práticas e discursos preconceituosos ou, ao menos, a crítica a eles - mais constante. Vale dizer que a própria criança poderá também estimular seja a reeducação dos pais, uma vez que também os ensinam, bem como a dos seus professores.

Para a aplicação da metodologia - passível de ser adaptada para o ensino fundamental e mesmo para o ensino médio -, a palestra sob a forma de "diálogo participativo" é o meio indicado, empregando-se linguagem adequada à clientela, evitando-se as argumentações paternalistas. ${ }^{3}$ A base ou pressuposto da proposta é o reconhecimento da diferença, com o objetivo de inverter o processo que tende a associar tal reconhecimento aos estereótipos negativos. Ou, em outras palavras, o reconhecimento da diferença deve ser construído no sentido da "valorização" e posterior "naturalização"4 dessa diferença, para que a igualdade subjacente seja ressaltada. Da mesma maneira, como pretendemos utilizar uma linguagem adequada à faixa etária da educação infantil, vejo como imprescindível organizar a proposta valendo-se de outros recursos didáticos que permitam a manipulação do concreto.

A princípio, pensou-se em trabalhar com formas geométricas, como cubos e bolas de cores diferentes. Porém, considerou-se que esse tipo de recurso didático, por ser muito utilizado, poderia não causar o impacto e interesse necessários para a discussão do tema. Também, a relação entre objetos inanimados e seres vivos, com destaque para a percepção da diferença, poderia tornar-se forçada. Outra proposta, sugerindo a presença de pessoas de cores diferen-

\footnotetext{
${ }^{3} \mathrm{O}$ paternalismo é antes um discurso do que uma prática ou,
} em outros termos, é um discurso que tem expressão na prática cotidiana. Esse contexto caracteriza-se por apelos emocionais àqueles que praticam o racismo, fazendo especialmente referências ao passado escravocrata e à obrigação e necessidade de os negros, em virtude disso, serem tratados com certa "condescendência". No limite, esse discurso justifica um tratamento nãoigualitário. Na vida cotidiana, marcada pelo conflito e pela contradição, esse discurso linear não consegue mais obter a eficácia que talvez tenha obtido algum dia.

4 "Naturalização", entre aspas, por se tratar de palavra empregada no senso comum, mas aqui empregada no sentido de ser inerente à condição humana, socialmente construída. 
tes - brancos, negros, mestiços - durante a palestra, também foi considerada inadequada. Consideramos que a presença de tais pessoas, sem que antes fosse desenvolvido um trabalho de mediação, poderia reforçar imagens falsas na medida que, conforme os estudos sobre relações raciais têm mostrado, o ideal estético não apenas é imposto pelo branco, mas introjetado pelos negros. Além do mais, atributos como "belo", "feio", "alto", "baixo", "simpático", "chato", caracterizando pessoas, poderiam interferir na indução do raciocínio das crianças. Em seguida, pensou-se em utilizar flores diferentes como rosas, margaridas, cravos, palmas. Contudo, da mesma maneira que a presença de pessoas diferentes, poderia surgir um "convidado não esperado": a preferência de cada um por essa ou aquela flor, quando contrapostas.

Depois de considerar-se as várias alternativas e os seus limites, chegou-se ao que pareceu mais próximo da "neutralização" da preferência e do gosto pessoal, que se formam a partir das relações sociais que se estabelecem ao longo da vida. Concluiu-se que se deve utilizar como recurso didático seres vivos, nãohumanos, mas da mesma espécie e de cores diferentes.

\section{0 material didático escolhido e o trabalho de mediação}

\footnotetext{
Margaridas: brancas, vermelhas, alaranjadas.

Rosas: vermelhas, amarelas, brancas ou corais.

Cravos: brancos e vermelhos.

Pintinhos: amarelos, brancos, pretos ou rajados.

Coelhinhos: pretos, rajados, marrons ou brancos.

Periquitos: azuis, amarelos, brancos ou verdes.
}

O "jardim" e a "bicharada" são apresentados às crianças, agrupados segundo o critério definido, e nesse momento deve ser estabelecido um diálogo simples em que a tônica seja a questão da igualdade e da diferença e de como é plenamente possível a convivência entre esses termos aparentemente díspares. Sem dúvida, a criatividade e o preparo para lidar com a temática racial, daquele que conduz a palestra, podem alterar os seus resultados.
Agora, vou apresentar a vocês a família do senhor coelho. Este se chama... este... e este... Olhem só! Vocês estão percebendo? Eles têm cores diferentes! São todos coelhos, não são? Mas este aqui é branquinho, este é marronzinho e este é pretinho! Quem adivinha a diferença? Vocês acertaram! A diferença está na cor! Porque todos são coelhos!

Esse é o diálogo imaginado e que pode ser estabelecido, com um desenrolar bastante provável. A cada grupo de flores e animais, a condução da conversa deve ser a mesma, até que chegue o momento decisivo, caso haja ou não a existência de um problema concreto, vivenciado na sala de aula, de discriminação e preconceito raciais:

Se a gente olhar aqui na sala, será que nós podemos encontrar um exemplo igual ao que nós percebemos com os coelhos, os periquitos, os pintinhos, as rosas, os cravos?

No caso de salas de aula com a presença de crianças negras, a discussão deve ser encaminhada para o reconhecimento de que todos ali são crianças e, como tais, são todos iguais, por meio de exemplos concretos. ${ }^{5}$ Prevê-se que, no final, as crianças reconheçam a diferença de cor e a igualdade fundamental.

Nas situações de sala de aula onde não há a presença de crianças negras, a proposta não é invalidada. Afinal, se a construção da identidade implica relações, não se pode ou não se deve abrir mão do aprendizado e reconhecimento da diferença, mesmo em salas constituídas apenas por crianças brancas,

${ }^{5}$ Deve-se atentar para a possibilidade de as crianças negras não se reconhecerem como tais. Não há critérios objetivos e definitivos de classificação racial, o que torna a questão do autoreconhecimento mais complexa. Ao professor caberá perceber se ocorrem problemas dessa natureza e decidir se estenderá o trabalho de mediação. A previsão é que, se o preconceito das crianças brancas for enfrentado com argumentos racionais, a postura de defesa das crianças negras - que se expressa, muitas vezes, na auto-rejeição - será modificada. 
admitindo-se a existência de problemas raciais no país. Além disso, é possível manter a mesma dinâmica de reconhecimento da igualdade e da diferença a partir de exemplos colhidos fora dos limites da sala de aula, como na própria escola ou na vizinhança.

Como se trata de proposta cujos resultados podem ser avaliados a médio e longo prazos, como recurso auxiliar de acompanhamento da experiência, definiu-se que desenhos feitos pelas crianças, antes e depois do conteúdo desenvolvido no trabalho de mediação, ${ }^{6}$ podem ser analisados de maneira comparativa. Esse recurso auxiliar foi inspirado em metodologia empregada por Gusmão (1993). ${ }^{7}$ A adaptação dessa metodologia deu-se no sentido de considerar que todas as crianças, independentemente de cor, são capazes de expressar por meio de desenhos a ideologia racista que permeia as relações sociais no Brasil. Se é possível perceber os efeitos legitimadores da dominação branca e a negação da diferença no desenho

${ }^{6} \mathrm{O}$ conteúdo deve, no meu entender, ser constantemente retomado. Imagina-se que a "metodologia do desenho" deva ser aplicada, ao menos na primeira vez, como atividade proposta às crianças de maneira direta: "Hoje vamos desenhar crianças negras e brancas que nós conhecemos". Para que os resultados obtidos sejam bem avaliados a partir de desenhos ou outros tipos de manifestações, deve ser assegurada uma margem de tempo após a aplicação da metodologia. Além disso, deve ser considerado se os pais já foram orientados na mesma perspectiva.

${ }^{7}$ A autora utilizou-se de imagens do universo infantil como fonte complementar de pesquisa antropológica. Mesmo considerando a ausência de metodologia definida, mas buscando subsídios de procedimentos e resultados obtidos em recursos como a fotografia e a filmografia, Gusmão interpretou imagens contidas em desenhos de crianças de uma comunidade rural negra, relacionadas com o contexto das relações vividas entre brancos e negros. Segundo ela, "numa sociedade multirracial e sem dúvida racista, a ideologia se manifesta subjetivamente nas imagens desenhadas, representando o espaço da vivência.[...]. Os desenhos das crianças negras de Campinho, em seus aspectos legitimadores da dominação branca e destruidores de uma consciência negra, negam o direito à diferença" (Gusmão, 1993, p. 79). infantil, considerou-se que seja também possível, após o desenvolvimento e o "reforço" do trabalho de enfrentamento de práticas racistas intra-escolares, captar nos desenhos o processo inverso. Ou seja, depois do trabalho desenvolvido, espera-se poder perceber, por meio dos desenhos, o processo de construção de uma ideologia que reconheça e aceite a diferença e que seja questionadora da dominação.

Ante a complexidade da questão racial, a proposta desenvolvida parece bastante simples. A princípio pode parecer óbvia, como, aliás, por vezes, o debate sobre a situação dos negros no Brasil e a sugestão de caminhos para o enfrentamento do problema ${ }^{8}$ são considerados. No entanto, se tudo fosse tão manifesto e evidente, passos decisivos teriam sido dados na perspectiva de sua superação. ${ }^{9}$ A propósito, as palavras de Saviani, referidas ao conteúdo da escola elementar, são válidas nesse contexto: "como é freqüente acontecer com tudo o que é óbvio, ele acaba sendo

${ }^{8}$ Embora essa afirmativa surpreenda o leitor interessado, o certo é que a alegação de "obviedade", que marcaria o debate da questão racial, é bastante comum. É uma temática desprestigiada, por não conferir prestígio acadêmico, e o conhecimento produzido por uns poucos não desperta o interesse de um grande número de pessoas, a não ser em contextos históricos bem definidos, como o atual. Em geral, essa alegação expressa o descompromisso político com o enfrentamento do problema. Também é sintomática da impotência ante o que é considerado "sem solução" ou “insuperável”. Isso porque ainda são poucos os estudos que buscam ultrapassar o nível da constatação e da denúncia da situação dos negros no país, que se configura num círculo vicioso aparentemente impossível de se romper.

${ }^{9} \mathrm{O}$ significado que confiro ao termo superação não é o mesmo que de "solução" ou "liquidação" do problema racial. Diz respeito, sobretudo, à mudança de determinada situação ou da conformação das relações raciais no País. Também não se limita à dimensão superestrutural ou ideológica da realidade, na qual a escola se insere, por ser uma das instituições que veicula concepções preconceituosas sobre os negros. Há implicações infraestruturais que não podem ou devem ser menosprezadas no processo de contínua transformação a que essa realidade está sujeita. 
esquecido ou ocultando, na sua aparente simplicidade, problemas que escapam a nossa atenção. E esse esquecimento, essa ocultação, acabam por neutralizar os efeitos da escola no processo de democratização" (Saviani, 1991, p. 23).

No entanto, a "simplicidade" da proposta está embasada numa opção teórica: todo homem, social por definição, atua no sentido de transformar o meio em que vive, para garantir a sua sobrevivência e reprodução. Trata-se de uma ação refletida. Em outros termos, é inerente ao homem agir e refletir sobre a realidade por ele criada e transformada. Por essa razão, trabalho (ação) e cultura (produtos materiais e espirituais da ação, como o pensamento, a reflexão, as ideologias) conformam as dimensões infra-estruturais e superestruturais dessa realidade que, além de serem indissociáveis, são constantemente transformadas. Contudo, ao longo da história e a partir da realidade construída pelos homens, essas dimensões não estabelecem relações de reflexo, mas de contradição, sobretudo quando a dimensão relativa ao trabalho é marcada pelo signo da exploração.

Uma vez que tratar de educação implica lidar com a dimensão superestrutural ou ideológica, qualquer proposta que reivindique uma suposta diferença cultural de brancos e negros me parece problemática, por desconsiderar a dimensão infra-estrutural. É nesse sentido restrita, limitada e ingênua. Do mesmo modo, pode soar ingênua, taxativa e forte qualquer proposta que reivindique para a educação ou para a escola o poder de solucionar o problema racial e os problemas da sociedade. Na verdade, só a partir de uma concepção da cultura como processo estático e dissociado do trabalho humano e das relações sociais estabelecidas é possível fazer a reivindicação da diferença cultural de negros e brancos. Ela mascara o fato de os grupos étnicos diferentes partilharem dados culturais entre si, como expressão de formas semelhantes ou não de inserção no "mundo do trabalho". ${ }^{10}$

${ }^{10}$ Nesse sentido, caberia refletir sobre o que tem sido chamado por "cultura negra" e sobre em que residiria a sua "especificidade".
Não quero dizer que a reivindicação da diferença cultural, apesar de restrita e limitada, não seja uma tática política importante para chamar a atenção sobre a diferença entre negros e brancos e para a desigualdade, discriminação e preconceito decorrentes das relações estabelecidas entre os dois segmentos. No entanto, a manipulação da diferença, sem que seja considerada a igualdade subjacente, pode levar ao aprofundamento da tensão racial e, o que é pior, ao paradoxo de, na luta pela cidadania, serem reforçadas as desigualdades e diferenças irrelevantes para o cumprimento do objetivo estratégico, que é a transformação social (Valente, 2002).

Contudo, a complexidade desse debate sobre a manipulação política de símbolos de identidade demanda níveis avançados de conhecimento e do processo educativo inerente à militância no Movimento Negro. Aos militantes cabe propor táticas políticas apropriadas e eficazes para enfrentar o racismo, mesmo que sejam circunstanciais. Mas, como estudiosa da questão, não posso deixar de apontar os limites dessas táticas e os problemas que são esquecidos, ocultados ou que escapam à atenção de alguns.

No caso de nossa proposta metodológica para o enfrentamento do racismo na educação infantil, parece-me suficiente que a escola possa assumir a mediação do reconhecimento da diferença fenotípica, tarefa que já é bastante complexa. Afinal, é a aparência ou "marca" (Nogueira, 1985) que desencadeia, em maior ou menor grau, dependendo das nuanças da cor negra, as manifestações de preconceito e discriminação raciais que, por sua vez, cumprem funções precisas de controle do acesso aos meios de produção e aos produtos do trabalho social.

\section{Rápidos comentários sobre a proposta experimentada}

As linhas gerais da proposta são eminentemente teóricas, exigindo, portanto, operacionalização. Apenas a prática poderá trazer elementos novos à reflexão, estabelecendo o movimento de mútua fecundidade entre esses planos, por definição indissociáveis. 
Tenho insistido para que o vínculo entre teoria e prática seja mantido, evitando-se com isso que a proposta se esvazie em um ativismo superficial e no espontaneísmo inconseqüente. Inúmeras possibilidades para o exercício da criatividade estão abertas e poderão ser incorporadas à proposta original. No entanto, só com o conhecimento efetivo da produção teórica sobre as relações raciais no Brasil, e de outros estudos pertinentes à compreensão do assunto, é possível que os resultados esperados sejam alcançados.

A proposta foi "ensaiada" em poucas oportunidades. Algumas situações vividas ou testemunhadas merecem ser relatadas, como indicativos dos cuidados que deverão nortear a sua aplicação. Apesar de não ter sido desenvolvida na íntegra, é possível apontar resultados preliminares, que parecem ser bastante satisfatórios para o cumprimento dos objetivos a que a metodologia se propõe.

A primeira "palestra" realizada obteve bons resultados. ${ }^{11}$ Como material didático, foram utilizados margaridas, pintinhos e coelhinhos de várias cores. O recurso aos desenhos não foi utilizado como esta-

${ }^{11}$ Professoras de uma escola comunitária em Campo Grande (MS) solicitaram colaboração no sentido de enfrentar um problema que estava ocorrendo na sala em que lecionavam: uma das crianças estava sendo discriminada pelas demais, por ser negra. Tratava-se de um menino, filho da funcionária da portaria da escola, que, além de estar sendo excluído das brincadeiras infantis, sentia-se constantemente ridicularizado com as alusões à sua cor. Exemplo disso era que, ao comerem um chocolate ou ao escreverem na lousa, as crianças diziam estar comendo o garoto, ou nele escrevendo.

${ }^{12}$ As crianças fizeram desenhos que foram oferecidos como agradecimentos ao professor e como recordação da sala de aula. As professoras orientaram para que elas se auto-representassem nesses desenhos, mas a temática de fundo foi a festa junina que aconteceu na época. De qualquer maneira, deve-se dizer que o desenho do menino negro discriminado apresenta marcas distintivas, quando comparado aos desenhos das demais crianças. É o único desenho em que as dimensões da fogueira, das bandeirolas, enfim, de símbolos juninos, são maiores do que o auto-retrato desenhado. va na proposta original. ${ }^{12}$ Os diálogos foram conduzidos conforme o previsto. Em certo momento, o professor disse ter resvalado no paternalismo: a fim de aproveitar a fala de uma criança, o professor propôs um tratamento religioso ou "cristão" do preconceito racial, projetando sua superação na esfera espiritual: "Papai do céu não acha certo essas atitudes".

Embora o tratamento religioso seja uma das maneiras de se abordar a questão, os educadores certamente contam com recursos mais racionais para tratar de uma questão que prima pela ambigüidade e sutileza. Nesse nível de escolaridade, certamente não poderemos usar tais argumentos de uma maneira plena, mas poderemos começar a introduzi-los, como tentamos mostrar mais adiante ao comentar os problemas que surgiram na segunda palestra.

Em outra oportunidade, vale ressaltar a reação de uma das crianças durante o desenvolvimento da proposta. O material didático foi o mesmo utilizado na primeira vez. ${ }^{13}$ Após o reconhecimento das diferentes cores de margaridas, o professor disse ser possível fazer um "jardim de crianças", que tinham várias cores. Outra professora sugeriu, imediata e criativamente, que as crianças formassem um buquê. Em seguida, como acreditasse ter concluído o trabalho de mediação, a professora perguntou:

\footnotetext{
- Por que vocês acham que o negro tem a pele desta cor?

- Porque elas são feitas de porcaria! respondeu impulsivamente uma criança branca.
}

Segundo os professores, aquela manifestação contundente causou "surpresa", apesar de conhecerem as várias formas que assumem as atitudes de preconceito e discriminação raciais. Isso porque se tratava da incorporação de uma noção racista por uma criança de 5 anos. Para dar continuidade à "palestra", foi necessário um certo esforço por parte da professora para recompor-se e enfrentar a situação de maneira tranqüila. Seguiu, então, explicando que aquela

\footnotetext{
${ }^{13}$ A metodologia dos desenhos não foi empregada.
} 
cor era consequiência de o sol ser muito quente na África, o continente de origem dos negros.

Alguns comentários podem ser feitos sobre esse "ensaio", no sentido de que os problemas que surgiram possam ser evitados numa outra oportunidade. Um desses problemas diz respeito à surpresa ante a manifestação de racismo da criança branca; o outro, a resposta dada para explicar a cor dos negros. Em primeiro lugar, deve-se dizer que não se pode negligenciar o fato de estarmos tratando de proposta que busca intervir na educação infantil, que deve ser conhecida em suas especificidades, mas que é informada pela educação obtida pelos adultos. A manifestação da criança de 5 anos, na verdade, expressou a incorporação de uma noção racista ao que tudo indica elaborada no nível da socialização primária, e que se coloca como um problema a ser enfrentado inclusive pela socialização secundária. Porém, considerandose a faixa etária de atendimento da educação infantil, bem como a idade e grau de escolaridade dos pais, é possível admitir que a escola, quer pela omissão, quer pelo "reforço", ${ }^{14}$ deva ser também responsabilizada pela transmissão de preconceitos.

Porém, deve-se recordar que tanto a identidade negativa dos negros como a identidade dos brancos resulta de um processo relacional, envolvendo os dois segmentos raciais. Nesse sentido, a manifestação da criança branca, além de expressar o processo de aprendizado precoce de imagens falsas e negativas sobre os negros, traz problemas não só para a construção da auto-imagem da menina negra discriminada em sala de aula, mas também para a construção da criança branca alimentando os seus preconceitos. Caso a criança que expressou a noção racista fosse negra, seria possível entender sua atitude como introjeção ou incorporação de concepções falsas sobre si. No entanto, diria pouco sobre a maneira como o "outro", que é branco, participa dessa construção e como constrói a sua identidade em oposição à dos negros. Co-

${ }^{14}$ Esse "reforço" se daria pela ação direta, via currículo, material didático e pelos corpos docente e discente. nhecidos os mecanismos das relações interétnicas no país, não me parece que uma manifestação racista deva causar "surpresa", seja o emissor uma criança ou adulto, branca(o) ou negra(o). Assim, o episódio parece chamar a atenção para o fato de que não se pode pensar a questão racial apenas em sua especificidade negra, como querem alguns militantes e estudiosos, na medida em que, necessariamente, essa questão envolve brancos. Também não se pode pensar na especificidade infantil sem que ela esteja referida ao "universo adulto" e à sua complexidade em termos raciais e de classe.

Em segundo lugar, no tocante à resposta sobre a cor dos negros, ao que parece, a "surpresa" ante a manifestação racista resultou numa argumentação improvisada e embasada em conceitos falsos. Ao tentar explicar a cor dos negros pelo fato de o sol ser muito quente na África, a professora estava repassando, sem crítica, uma concepção determinista, ultrapassada e incorreta do ponto de vista científico. É preciso dizer que a resposta da professora fazia um certo sentido, na medida em que as mutações biológicas, ao possibilitarem combinações genéticas (que aumentam a freqüência de certas características), sofrem a influência de condições ambientais. Contudo, deve-se considerar que discutir questões de genética junto às crianças é temerário, sem a utilização de uma linguagem adequada. Além disso, deve-se contar com o desdobramento das explicações. Afinal, é possível a criança perguntar: onde não há sol, não há negros? Por que os negros brasileiros, depois de tanto tempo, são iguais aos negros africanos? Quais as diferenças e semelhanças entre Brasil e África atuais? Para que seja mantida a coerência da proposta é necessário evitar o falseamento de qualquer questão. Não se pode pretender enfrentar o racismo, que se baseia em concepções falsas, incorrendo em outros erros similares. Naquela oportunidade, a professora parece ter considerado mais importante dar uma resposta, fosse correta ou não, para contrapor-se ao comentário preconceituoso, já que toda a proposta poderia ser comprometida junto às outras crianças. Nesse sentido, sua atuação pode ser justificada. Mas 
é preciso não subestimar a reação das crianças ante as informações que lhes são repassadas. Por essa razão, é necessário investir em um melhor preparo e estudo para responder às eventuais dúvidas que possam surgir e, taticamente, evitar tocar em questões sobre as quais não se tem domínio ou conhecimento. O procedimento que me parece mais adequado é a busca de auxílio junto a outros campos do conhecimento ${ }^{15}$ para as reformulações que se fizerem necessárias na proposta original, dado o seu caráter "interdisciplinar".

Como resposta à questão: "Por que vocês acham que o negro tem a pele desta cor?", para as crianças da faixa etária da educação infantil, imagina-se que bastaria dizer que os negros possuem no corpo, em maior quantidade do que os brancos, uma substância ou pigmento que dá cor à pele e que tem o nome de melanina. Utilizando-se flores para explicar como a presença de um pigmento pode "colorir", poderia ser feita a experiência de ser colocada uma rosa branca em um tinteiro, até que a flor adquirisse a cor da tinta.

Ilustrativo de como a proposta-matriz pode incorporar novas idéias e sugestões para que o seu objetivo seja atingido da melhor maneira possível, foi a utilização da leitura de um livro infantil, como mais um recurso didático da metodologia, aplicada em outra situação na qual uma menina negra vinha sendo discriminada pelos colegas. O livro escolhido discorre sobre a história de um coelhinho branco que quer ficar preto e indaga a uma menina negra qual o segredo de sua cor. Depois de várias tentativas, e sem que a menina consiga dar uma resposta satisfatória, o coelho fica sabendo do "segredo": ele deveria ter filhotes com uma coelhinha preta para que eles pudessem ser brancos, pretos ou malhados. No fim da his-

${ }^{15} \mathrm{Na}$ situação relatada, um excelente apoio poderia ser buscado nos conhecimentos acumulados pela história, sociologia, antropologia e biologia. Tratando-se de educação infantil, o conteúdo de nossa proposta pode ser desenvolvido nas aulas de "ciências", "estudos sociais", "matemática" (noções de conjunto) ou outras, dependendo da maneira como se organiza o currículo. tória, a menina negra é escolhida como madrinha de um dos filhotes de coelho, um coelhinho preto.

Seguindo a orientação da proposta, de que era preciso utilizar recursos didáticos que causem impacto, enquanto a professora lia a história para um atento público infantil, utilizando-se de efeitos cênicos dava a impressão de estar tirando os coelhospersonagens do interior do livro. As crianças ficaram entusiasmadas com o que viram e aprenderam. Finalizando a segunda experiência, foi realizada uma "cerimônia" na sala de aula: o "batizado" do coelhinho preto, o filhote do personagem principal da história infantil. ${ }^{16}$ Todas as crianças estavam animadas e contentes. Orgulhosa, a menina negra, antes discriminada como no livro, foi a madrinha.

Há depoimentos das professoras de que, depois dessa experiência, as crianças assumiram atitudes francamente anti-racistas. Exemplo de que o novo aprendizado estava sendo construído foi o fato de a boneca negra passar a ser disputada pelas crianças na escola. Também parece demonstrativo desse aprendizado que, segundo outro relato, uma criança, ao ver uma radiografia, tenha comentado com um médico que todos são iguais por dentro, mesmo que por fora tenham cores diferentes.

Cabe informar que foi realizada uma palestra para os pais das crianças da educação infantil, com o objetivo de esclarecê-los sobre as situações de preconceito e discriminação raciais que estavam sendo enfrentadas em sala de aula. Deve-se destacar que os pais de crianças negras e mestiças, nessa oportunidade, deram depoimentos sobre os problemas que eles próprios enfrentaram na infância, ou então afirmaram a inexistência do racismo ${ }^{17}$ no país. Como disse

16 O livro infantil é de autoria de Ana Maria Machado, publicado pela Editora Melhoramentos e intitulado Menina bonita do laço de fita.

${ }^{17}$ Uma ocorrência que merece registro foi a negativa da mãe da menina discriminada em reconhecê-la como negra, enquanto a criança reprocessava a sua identidade, após a execução da metodologia. 
anteriormente, essa proposta metodológica não prescinde da integração dos educadores, pais e professores no combate ao racismo. Sem essa integração, a metodologia pode não ser eficaz.

\section{À guisa de considerações finais}

Como escrevi em outra oportunidade (Valente, 2003b), atualmente parece oportuno insistir na reflexão sobre as políticas afirmativas de caráter universal e específico, nos diferentes níveis de ensino. No meu entender, é uma falsa questão contrapô-las, como se excludentes fossem. Por isso, o equívoco do debate sobre as cotas não consiste apenas "em enfatizar a modalidade mais polêmica das políticas de ação afirmativa" (Silvério, 2002, p. 220). De fato, ação afirmativa e cotas são coisas diferentes. ${ }^{18}$

A contraposição entre políticas de ação afirmativas "universais" e "específicas", ou estabelecer a polêmica "em torno da oposição entre políticas de ação afirmativa e políticas universalistas/sociais mais amplas" (Moehlecke, 2002, p. 213) implica escorregar na armadilha da razão dualista, tantas vezes criticada. A afirmação de que "enquanto o ensino fundamental e médio exigem uma universalização, o ensino superior necessita de medidas que garantissem o ingresso de certos grupos dele sistematicamente excluídos [...]" (idem, p. 213-214), parece negar o acúmulo de conhecimento que se tem sobre esses níveis de ensino no tocante ao tratamento da questão racial.

O que os dados apresentados no início deste texto estariam a demonstrar, senão a necessidade de serem implementadas ações afirmativas específicas na educação básica? Ao contrário do que pensa

${ }^{18}$ Sabrina Moehlecke (2002), em artigo que oferece uma contribuição importante para a história da ação afirmativa no Brasil, explicita essa diferença. Entretanto, confunde o leitor ao escrever que propostas para responder ao problema da discriminação e desigualdades raciais "foram as políticas de ação afirmativa, também designadas “política de cotas"” (p. 198), admitindo serem sinônimas.
Silvério (2002, p. 220), as políticas universalistas não têm obtido o sucesso almejado porque não vêm sendo articuladas às ações específicas.

A discussão sobre os negros no Brasil, historicamente, tanto no senso comum como em meios acadêmicos, vem sendo conduzida de forma a polarizar a "questão social" e a "questão racial". No meu entender, trata-se de discussão há muito superada, a não ser nas perspectivas idealistas...

Há muito tempo os conceitos de "classe" e "raça" 19 vêm mobilizando a preocupação de pesquisadores. A bibliografia conhecida e dedicada à temática confirma isso. ${ }^{20}$ "Raça" é ainda importante nos estudos sobre as relações entre brancos e negros, primeiramente porque corresponde a uma noção "popular" que se confunde com a noção "técnica" das ciências sociais, quando essas procuram resguardar as interpretações dos sujeitos que estuda. Além disso, "raça" como construção social das diferenças fenotípicas torna-se um dos aspectos mais significativos do processo de identificação étnica ou da etnicidade. Esta última, também uma construção que engloba a idéia de filiação racial, ao referir-se à percepção das diferenças ou à escolha de identidades étnicas e raciais é decisiva para a compreensão daqueles que são classificados, mas, sobretudo, daqueles que classificam. Dessa maneira, torna-se um conceito analítico importante.

Mas esse processo de identificação racial "ascende da terra ao céu" (Marx \& Engels, 1986, p. 37): ${ }^{21}$

${ }^{19}$ A afirmação de Silvério de que "só muito recentemente vozes dissonantes têm chamado a atenção sobre a singularidade de nossas relações raciais" (2002, p. 223) aponta para o contrário.

${ }^{20}$ No reconhecimento dessa produção, o papel do pesquisador não deve ser confundido com o do militante. Ao primeiro cabe o compromisso com a produção transformadora do conhecimento, a utilização crítica de instrumentos teóricos e metodológicos e o cuidado para não se perder num ativismo político, que não se confunde com o compromisso necessário.

${ }^{21}$ Numa crítica ao idealismo, Marx e Engels continuam: "não se parte daquilo que os homens dizem, imaginam ou repre- 
o contexto histórico no qual se manifesta é o da sociedade capitalista e das relações de classe que lhe é peculiar. Ou seja, a especificidade racial só pode ser compreendida à luz dessa organização social. Não se trata "disso ou daquilo" (outro dualismo!) ou de uma combinação que pressupõe soma, mas de contradição. A articulação de valores universais - isto é, valores do capitalismo, marcado por concepções de mundo antagônicas - às especificidades etnoculturais permite que o espaço político não seja fragmentado e não seja degradada a democracia, possível somente quando um direito comum regula a coexistência das liberdades individuais e particulares (Valente, 2002, p. 77).

Valendo-me dos argumentos apresentados acima, políticas universais implicam políticas específicas, e vice-versa, em todos os níveis de ensino. Acredito ainda que a maior ou menor eficácia de políticas de ação afirmativas para os negros esteja inversamente relacionada ao nível de ensino, isto é, quanto antes o racismo, a discriminação e o preconceito forem enfrentados, melhores serão os resultados educacionais. ${ }^{22}$ Exige-se, portanto, pensar na universalização da educação infantil e em programas "redistributivos", como o Bolsa Família. Esse programa abriga hoje o extinto Programa Bolsa Escola que se propôs a universalizar o ensino fundamental e a exigir como

sentam, e tampouco dos homens pensados, imaginados e representados para, a partir daí, chegar aos homens de carne e osso; parte-se dos homens realmente ativos e, a partir desse processo de vida real, expõe-se também o desenvolvimento dos reflexos ideológicos e dos ecos desse processo de vida. E mesmo as formações nebulosas no cérebro dos homens são sublimações necessárias do seu processo de vida material, empiricamente constatável e ligado a pressupostos materiais" (1986, p. 37).

${ }^{22}$ Para José de Souza Martins, “de nada adianta adotar o regime de cotas na universidade se a escola elementar e a escola média continuarem na indigência em que se encontram. A decadente qualidade de ensino nesses níveis de escolarização é que constitui uma das principais fábricas de injustiça social neste país, e não só de injustiça racial” (2003, p. 3). contrapartida o controle da frequiência escolar, criando condições propícias para que medidas específicas sejam implementadas nacionalmente.

Mas para que seja garantida a "qualidade" desse processo há que se enfrentar os desafios na formação de professores, para que saibam lidar adequadamente com a questão. ${ }^{23} \mathrm{E}$ isso não se faz em cursos intensivos de capacitação nos finais de semana e sem que se leve em consideração, de um lado, o conhecimento acumulado sobre a temática, de outro, aquele "cristalizado" que por vezes falseia.

Por essa razão, a formação de professores da educação básica para o tratamento da questão racial nas escolas, abarcando o desenvolvimento de metodologias para a educação infantil e a implementação da Lei Ben Hur, nos níveis fundamental e médio, que torna obrigatório o ensino da história e da cultura afrobrasileira, envolve várias dimensões: desde o repensar sobre a política educacional até a "capilaridade" do processo que envolve os professores e os alunos nas salas de aula. Como pólos de um mesmo processo, ambos exigem uma "mudança de olhar" que se proponha a ver, entender, reagir, e não mais silenciar ante o racismo que se manifesta nos espaços escolares.

Uma agenda possível, no âmbito da educação formal, seria, num primeiro momento, tomar-se a política educacional do país como dimensão definidora de metas e objetivos que se pretende atingir no campo da promoção da igualdade racial, impondo-se recuperar os seus fundamentos legais. Entre outros, a Constituição Federal, as proposições doutrinárias que norteiam a Lei de Diretrizes e Bases da Educação Nacional, as Diretrizes Curriculares Nacionais para o Ensino Fundamental, as Diretrizes Nacionais para a

${ }^{23}$ Iniciativas pontuais de formação de professores vêm sendo desenvolvidas no país - como a proposta do Programa de Educação sobre o Negro na Sociedade Brasileira / Universidade Federal Fluminense; o curso Ibaa xé (em iorubá, “que isto possa ser aceito"), elaborado por Lucimar Rosa Dias e Fabiano Maisonnave, em Mato Grosso do Sul, e outras - que podem ser articuladas nessa ação de alcance nacional. 
Educação no Campo e os Parâmetros Curriculares Nacionais. Em outras palavras, essa formação "específica" não se descola da necessidade de uma formação "em geral" dos professores brasileiros, há tanto tempo reclamada.

Em seguida, considerando-se a implementação de ações educativas como a dimensão executiva dessa política, pode-se considerá-las como atividades que concretizam o que está definido na política educacional, buscando eliminar o dualismo teoria/prática, na medida em que uma não pode ser pensada sem a outra. Entretanto, no que diz respeito à instância na qual a estratégia se concretiza, há que se considerar os diferentes níveis em que isso se dá. Significa dizer que diversas ações institucionais podem ser empreendidas por meio das instâncias de mediação, como os programas sociais do governo federal. Mas é plural a maneira como essa política e essas ações serão decodificadas, na prática, nos estados e municípios da Federação, tanto no campo institucional, da sociedade política, como no campo da sociedade civil.

Em razão disso, ao se procurar politizar a ação educativa para a promoção da igualdade racial, articulando-a à política educacional, não cabe tergiversar na discussão sobre o poder e sobre a conformação do Estado - envolvendo sociedade política e sociedade civil, que se dá em diferentes patamares de representação (federal, estadual, municipal) e é marcada por conflitos e por interesses antagônicos. E, nesse caso, também não vale escamotear o fato de que se deva tomar "partido": opções políticas devem ser feitas sobre o sentido e o significado que se pode imprimir a essas ações.

Dito de outra forma, para implementar a Lei Ben Hur poder-se-ia, por exemplo, obrigar que as escolas, através de seus professores, o façam, e não resta dúvida de que se trataria de uma ação que concretiza a política educacional. Mas apenas num nível, talvez o mais elementar, sujeito a resistências, conhecidos os mecanismos das relações raciais no Brasil. A opção política para a superação desse nível em que tal política ganharia concretude pode ser: estabelecer que essa ação seja revestida de conteúdo significativo que implique o aprendizado para além dos mediadores institucionais locais, e que tenha como foco não apenas a "comunidade escolar" em todos os níveis, mas a extrapole.

Como decorrência dessa opção, tal aprendizado deve fazer parte do planejamento pedagógico das escolas, considerando:

a) o contexto social em que estão inseridas, a partir do diagnóstico de valores locais;

b) as demandas da escola, do indivíduo, da família e da sociedade envolvente, ou seja, as demandas individuais e principalmente as coletivas;

c) a mobilização dessas demandas, tomadas como prioritárias em diferentes momentos e com diferentes graus de intensidade, na perspectiva de se construir um projeto coletivo, calcado em processos participativos e democráticos.

Na verdade, essa opção política foi feita, se considerarmos as Diretrizes Curriculares Nacionais "que orientarão as escolas brasileiras dos sistemas de ensino na organização, na articulação, no desenvolvimento e na avaliação de suas propostas pedagógicas" (Brasil, Conselho Nacional de Educação, 1998, p. 31).

Assim, para que a estratégia de promoção da igualdade racial não seja abortada, impõe-se partir do conhecimento acumulado, do pensado e do vivido por professores e sociedade envolvente, que não são imunes ao racismo. A superação do senso comum é possível quando embasada num "acerto de contas" com a formação recebida e cristalizada.

Definida a direção política que se pretenda imprimir a essas ações, não se pode desconsiderar a importância de que essa opção seja partilhada. Desse modo, deve-se fazer uma escolha que também exija a intervenção sobre as concepções de senso comum da "comunidade local" onde se pretenda atuar, definindo medidas para a sua formação e procurando conhecer experiências de mobilização comunitárias já em andamento, para potencializá-las. No caso em questão, impõe-se a formação dos professores em exercício e a capacitação daqueles em 
formação, sugerindo que seu desenvolvimento seja uma contrapartida de adesão aos programas sociais do governo.

A formação de professores da educação básica, particularmente os responsáveis pelo ensino das disciplinas História e Estudos Sociais, em exercício, visaria:

a) sensibilizá-los para a importância de incorporar ao currículo existente recorte que destaque a história e cultura afro-brasileira - com base no conhecimento acumulado, mas sujeito a transformação;

b) trocar experiências, aprimorá-las e difundir aquelas voltadas para a valorização do respeito à diferença;

c) discutir a necessidade de formação específica sobre história e cultura negras.

A estrutura pedagógica dessa formação deveria privilegiar o currículo existente e as inúmeras possibilidades que podem ser abertas para tratar a questão racial, ou seja, temas referentes à conformação histórica das relações raciais no Brasil. O formato de seminários em que o diálogo e a troca de experiências sejam a tônica parece ser uma boa sugestão. Dessa maneira, as resistências poderão ser minimizadas. $^{24}$

$\mathrm{Na}$ formação dos futuros professores, os cursos de pedagogia, normal superior e demais licenciaturas deveriam ser os focos de atenção. Sabidamente, esses cursos têm por clientela a população mais carente. Entretanto, seus formandos têm a inserção profissional mais apropriada para desenvolver ações estratégicas no campo educacional. É indispensável a

${ }^{24}$ Nesse processo, parece-me imprescindível que sejam estabelecidas parcerias com instituições representativas da educação brasileira, especialmente União Nacional de Dirigentes Municipais de Educação (UNDIME) e Conselho Nacional de Secretários Estaduais de Educação (CONSED). Nas reuniões programadas dessas instituições poderia ser aberto espaço para apresentação da proposta que desencadearia o processo de mobilização. incorporação da temática racial nesses cursos. ${ }^{25}$ Desse modo, poderá ser estabelecida uma articulação dinâmica entre todos os níveis da educação brasileira (educação básica, média e ensino superior), com o envolvimento de várias áreas de competência da estrutura institucional, promovendo a formação de futuros profissionais da educação e daqueles que atuam como professores nas escolas municipais/estaduais brasileiras na discussão do tema.

Por fim, a constituição de um conselho consultivo, formado por setores do governo e da sociedade civil que trabalham com o tema, poderá permitir a conformação final do projeto de formação de professores, bem como o monitoramento, análise e avaliação das ações levadas a cabo.

Com a Lei Ben Hur e as Diretrizes Curriculares Nacionais para a Relação Étnico-Raciais e para o Ensino de História e Cultura Afro-Brasileira e Africana promoveu-se um avanço histórico, não isento de percalços futuros, como se pode entrever nessa "agenda possível". Mas vale a pena buscar superar quaisquer dificuldades na construção de uma sociedade antiracista.

ANA LÚCIA VALENTE, doutora em antropologia social pela Universidade de são Paulo (USP) e com pós-doutorado em antropologia na Université Catholique de Louvain, na Bélgica, atualmente é professora na Faculdade de Agronomia e Medicina Veterinária da UnB. Publicou: Ser negro no Brasil hoje (18 ed., Moderna, 2002); Educação e diversidade cultural - um desafio da atualidade (Moderna, 1999). Pesquisa atual: Desenvolvimento local sustentável em área remanescente de quilombo. E-mail: alefv@uol.com.br

\section{Referências bibliográficas}

BRASIL, Congresso Nacional, (1996). Lei no 9.394 de 20 de dezembro de 1996. Diário Oficial, Brasília, 23 de dezembro

${ }^{25}$ Pode ser promovida a partir de negociação com os reitores dessas universidades públicas, mediada pela Secretaria de Ensino Superior - (SESU/MEC). Também nas reuniões programadas do Conselho dos Reitores (CRUB) poderia ser aberto espaço para a apresentação da proposta que desencadearia o processo de mobilização. 
de 1996, p. 27.833-41. Estabelece as diretrizes e bases da educação nacional.

, (2003). Lei $\mathrm{n}^{\mathrm{o}} 10.639$ de 9 de janeiro de 2003.

Diário Oficial, Brasília, 10 de janeiro de 1996. Altera a lei $\mathrm{n}^{\circ}$ 9.394, de 20 de dezembro de 1996, que estabelece as diretrizes e bases da educação nacional, para incluir no currículo oficial da rede de ensino a obrigatoriedade da temática história e cultura afro-brasileira e dá outras providências.

BRASIL, Conselho Nacional de Educação, (1998). Diretrizes curriculares nacionais para o ensino fundamental. Diário Oficial, Brasília, 30 de março.

, (2004). Parecer $\mathrm{n}^{\circ} C N E / C P$ 003/2004, aprovado em 10 de março de 2004. Diretrizes curriculares nacionais para a educação das relações étnico-raciais e para o ensino de história e cultura afro-brasileira e africana.

BRASIL, Ministério da Educação, (1997). Parâmetros curriculares nacionais: pluralidade cultural, orientação sexual. Brasília: MEC/Secretaria de Ensino Fundamental.

GUSMÃO, Neusa Maria Mendes de, (1993). Socialização e recalque: a criança negra no rural. Cadernos CEDES, Campinas: Papirus, $\mathrm{n}^{\circ} 32$, p. 49-84.

MARX, K.; ENGELS, F., (1986). A ideologia alemã. $5^{\text {a }}$ ed.. São Paulo: Hucitec.

MARTINS, José de Souza, (2003). Cota para negros na universidade. Folha de S.Paulo, São Paulo, 25 maio, Opinião, p. 3.

MOEHLECKE, Sabrina, (2002). Ação afirmativa: história e debates no Brasil. Cadernos de Pesquisa, São Paulo, nº 117, nov., p. $197-217$
NOGUEIRA, Oracy, (1985). Preconceito racial de marca e preconceito racial de origem. In: —. Tanto preto quanto branco: estudos de relações raciais. São Paulo: T.A. Queiroz, p. 65-93.

PEREIRA, João B. B., (1987). A criança negra: identidade étnica e socialização. Cadernos de Pesquisa, São Paulo, nº 63, nov., p. 41-46.

SAVIANI, Dermeval, (1991). Pedagogia histórico-crítica - primeiras aproximações. São Paulo: Cortez \& Autores Associados.

SILVÉRIO, Valter Roberto, (2002). Ação afirmativa e o combate ao racismo institucional no Brasil. Cadernos de Pesquisa, São Paulo, no 117, nov., p. 219-246.

VALENTE, Ana Lúcia, (1998). Educação e diversidade cultural: algumas reflexões sobre a LDB. Revista Intermeio, Campo Grande (MS), n 4, p. 21-24.

VALENTE, Ana Lúcia, (2002). Os negros, a educação e as políticas de ação afirmativa. Revista Brasileira de Educação, $\mathrm{n}^{\circ}$ 19, jan-abr, p. 76-86.

VALENTE, Ana Lúcia, (2003a). Conhecimentos antropológicos nos parâmetros curriculares nacionais: para uma discussão da pluralidade cultural. In: GUSMÃO, Neusa Maria Mendes de (org.) Diversidade, cultura e educação. São Paulo: Biruta. p. 17-46.

VALENTE, Ana Lúcia, (2003b). O Programa Nacional de Bolsa Escola e as ações afirmativas no campo educacional. Revista Brasileira de Educação, no 24, p. 165-182.

Recebido em julho de 2004 Aprovado em outubro de 2004 


\title{
Resumos/Abstracts
}

\begin{abstract}
Ana Lúcia Valente
Ação afirmativa, relações raciais e educação básica

Com base em proposta metodológica de combate ao racismo na educação básica, desenvolvida com resultados positivos em escolas de Campo Grande (MS) e Belo Horizonte (MG), objetivou: a) indicar que esse nível de escolarização apresenta o quadro educacional mais grave para as crianças negras; b) refletir sobre as políticas afirmativas de caráter universal e específico, nos diferentes níveis de ensino, defendendo a perspectiva de que contrapô-las, como se excludentes fossem, é uma falsa questão; c) argumentar que a maior ou menor eficácia de políticas de ação afirmativas para os negros está inversamente relacionada ao nível de ensino, isto é, quanto antes o racismo, a discriminação e o preconceito forem enfrentados, melhores serão os resultados educacionais e; d) apontar os desafios para a formação de professores nessa perspectiva.
\end{abstract}

Palavras-chave: ação afirmativa; relações raciais; educação básica

\begin{abstract}
Affirmative action, racial relations and primary education
On the basis of the methodological proposal for combating racism in primary education, developed with positive results in schools in Campo Grande (State of Mato Grosso do Sul) and Belo Horizonte (State of Minas Gerais), we propose: a) to indicate that this level of schooling presents the most serious educational situation for black children; b) to reflect upon affirmative policies of a universal and specific character, in different levels of education, defending the perspective that setting them in opposition, as if they were exclusive, is a false question; c) to argue that the greater or lesser efficacy of policies of affirmative action for Negroes is inversely related to the level of education, that is, the earlier racism, discrimination and prejudice are faced up to, the better will be the educational results and d) to point to challenges for the formation of teachers in this perspective.

Key-words: affirmative action; racial relations; primary education
\end{abstract}

